\title{
The Development of the Japanese Psychiatric Nursing Assessment Classification System (PsyNACS ${ }^{\odot}$ )
}

\author{
Hirokazu Ito', Misao Miyagawa², Kazuhiro Ozawa ${ }^{3}$, Tetsuya Tanioka1*, Yuko Yasuhara1, \\ Mutsuko Kataoka4, Beth King5, Masahito Tomotake', Rozzano C. Locsin'1 \\ ${ }^{1}$ Department of Nursing, Institute of Biomedical Sciences Tokushima University, Graduate School, \\ Tokushima, Japan \\ ${ }^{2}$ Department of Nursing, Faculty of Health and Welfare, Tokushima Bunri University, Tokushima, Japan \\ ${ }^{3}$ Nursing Collaboration Center, Gifu College of Nursing, Gifu, Japan \\ ${ }^{4}$ Mifune Hospital, Kagawa, Japan \\ ${ }^{5}$ Christine E. Lynn College of Nursing, Florida Atlantic University, Boca Raton, Florida, USA \\ Email: *tanioka.tetsuya@tokushima-u.ac.jp
}

Received 10 October 2015; accepted 26 December 2015; published 29 December 2015

Copyright (C) 2016 by authors and Scientific Research Publishing Inc.

This work is licensed under the Creative Commons Attribution International License (CC BY). http://creativecommons.org/licenses/by/4.0/

c) (i) Open Access

\section{Abstract}

The purpose of this study was to develop the Japanese Psychiatric Nursing Assessment Classification System (PsyNACS) ${ }^{\odot}$. This study used the on-line survey method from February to April 2015. There were 644 respondents comprised of professional nurses with minimum qualification of 3 years' experience being in a psychiatric unit of a stand-alone 200-bed or more Psychiatric Hospital in Japan. Assessment items were derived from 211 specific items selected from nursing textbooks, excluding the North-American-Nursing-Diagnosis-Association (NANDA). The questionnaire contained Cover Letter, Demographic Data Sheet, and the PsyNACS ${ }^{\odot}$ questionnaire. There were 644 questionnaires accessed but only 435 were completed and valid. Item levels of importance were evaluated: 1) Unnecessary, 2) Not very important, 3) Important and 4) Very important. Data analysis used descriptive and multivariate statistics. Factor analysis (principal factor analysis, varimax rotation), the Kaiser-Meyer-0lkin (KMO) and the Bartlett's test of Sphericity assessed the adaptive validity of the factor analysis. Factor loadings were set at 0.4 or more for the configuration of items. Internal consistency and reliability were established using Cronbach's alpha coefficient. Mean factor points were calculated, including standard deviation, range, and confidence interval at $\mathbf{9 5 \%}$. Statistical significance was at 0.05 level. Nine Patient Assessment Data (PAD) with 2 to 5 Cluster Assessment Data (CAD) each were categorized. Thirty one CADs comprised the Patient Assessment Data: (PAD1) Psychological symptom and stress, (PAD2) Information about treatment, (PAD3) Function of eating and balance of water, (PAD4) Life and value, (PAD5) Vital signs and *Corresponding author.

How to cite this paper: Ito, H., Miyagawa, M., Ozawa, K., Tanioka, T., Yasuhara, Y., Kataoka, M., King, B., Tomotake, M. and Locsin, R.C. (2016) The Development of the Japanese Psychiatric Nursing Assessment Classification System (PsyNACS ${ }^{\odot}$ ). Open Journal of Psychiatry, 6, 20-33. http://dx.doi.org/10.4236/ojpsych.2016.61003 
health assessment, (PAD6) Self-care, (PAD7) Social support, (PAD8) Activity, sleeping and mobility capability, and (PAD9) Sexual function and sexual behavior. The PsyNACS ${ }^{\odot}$ is a classification of items assessing health care needs within the Japanese psychiatric nursing care environment, and also can be used in various psychiatric patient care situations in all psychiatric units.

\section{Keywords}

\section{PsyNACS, Psychiatric Nursing, Patient Assessment Data, Psychiatric Hospital}

\section{Introduction}

In 2011, the Japanese Government unveiled its health care policy focusing on five major diseases: malignant neoplasms, cerebral stroke, acute cardiac infarction, diabetes mellitus, and psychiatric diseases. The Japanese Government considers psychiatric diseases a major disease [1]. The psychiatric healthcare in-patient environment shows that the average hospital stay is longer compared to other countries [2]. Psychiatric disease does not only exhibit subjective symptomatology, but also includes functional disturbances, disability and social disadvantage [3]-[5]. Characteristics of psychiatric diseases are that the progression and remission repeatedly occur and the disease becomes chronic [6] forcing psychiatric patients to continually stay in hospitals rather than live in their communities [7] [8].

Furthermore, Japan is facing a super-aging society where the elderly population, older than 65 years old, accounts for more than $25 \%$ of the total population. This percentage is expected to increase to 40 percent by 2055 [9]. More than 50 percent of total in-patients at psychiatric hospitals are the elderly [10]. In addition, as they age, psychiatric patients, having physical complications associated with malignant neoplasms, after-effects of cerebral stroke and pneumonia, require increased nursing care practices for their physical care needs [11].

Generally, psychiatric hospitals in Japan, systematically collect patient information following methods set forth by the North American Nursing Diagnosis Association (NANDA) [12] [13] and the framework of nursing care needs from Henderson [14]. At psychiatric hospitals in Japan, the Orem's self-care theory of Nursing [15], focusing on supporting and meeting self-care needs of patients [16] [17], and the 14 basic needs according to Henderson, focusing on patients' needs, can be readily observed. However, there is no reference to a Japanese psychiatric nursing-care assessment data system reflecting the human health and nursing needs of Japanese psychiatric patients.

Patients' assessment data generated in general hospitals because aimed for somatic disorders, are not comprehensive enough or do not work well enough for psychiatric patients. Because of these inadequacies, some hospitals have added information to meet their assessment needs. To be cognizant of these diseases and cover all information necessary to respond to the demands of nursing care of psychiatric patients, it is important that a culturally-based psychiatric patients' assessment data system is designed and implemented.

Hospitals that introduce electronic health records can build a unique database of information for the assessment of patients cooperatively developed by engineers and other health care personnel of the hospital's medical information department [18]. With an electronic health record system, it is possible not only to use the database for the systematic processing of nursing-care activities, but also to comprehensively use the information which may be of relevance for other health care occupations for the purpose of assuring human health care [19]. However, in 2005, the introduction rate of electronic health records by psychiatric hospitals was under the 10 percent mark [20]. This shows that many hospitals have difficulty collecting the required information for adequately assessing patients, and developing and implementing nursing-care plans.

Therefore, in order to respond to the needs of Japanese psychiatric patients based on cultural-social backgrounds, medical treatments, nursing care, and post-discharge rehabilitation, a thorough assessment should be effortlessly and comprehensively conducted. Effective nursing-care can be provided through a method of holistic assessments of patients by clarifying their symptomatology characteristics of being a patient with psychiatric nursing care problems requiring nursing interventions.

The purpose of the study was to design and develop the Japanese Psychiatric Nursing Assessment Classifica- 
tion System (PsyNACS) ${ }^{\circledR}$.

\section{Methods}

\subsection{Description of PsyNACS ${ }^{\odot}$}

A descriptive correlational survey method was used to determine the clusters of assessment items that comprise the Cluster Assessment Data (CAD) and the Patient Assessment Data (PAD) of the PsyNACS ${ }^{\odot}$. The PsyNACS ${ }^{\odot}$ is composed of three levels or sections: The general data set is composed of 9 PADs, with each PAD having 2 to 5 CADs. There are 31 CADs derived from selected evaluation items. In order to investigate the items necessary for a psychiatric nursing-care assessment data, 211 assessment items were derived from specific assessment items based on selected theoretical models or frameworks of self-care theory by Orem-Underwood [17], the 14 basic needs by Henderson [14], Gordon's 11 functional health patterns [21] and items from the stress adaptation model by Stuart [22]. The level of importance of each indicator was evaluated as 1) Unnecessary, 2) Not very important, 3) Important and 4) Very important.

\subsection{Data Analysis}

Data analysis used descriptive and multivariate statistics to determine the distribution of items within the PsyNACS $^{\odot}$. Factor analysis (principal factor analysis, varimax rotation) was used in order to determine CAD together with the Kaiser-Meyer-Olkin (KMO) and the Bartlett's test of Sphericity to assess the adaptive validity of the factor analysis. Factor loadings were set at 0.4 or more for the configuration of items. Factor loadings of less than 0.4 were omitted because of its low-level importance.

Internal consistency and reliability of the assessment data scores was done using Cronbach's alpha coefficient. Mean factor points were calculated, including the standard deviation, range, and confidence interval (CI) at 95\%. Statistical significance was set at 0.05 level. All statistical analyses were performed using the SPSS for Windows software (version 20.0; SPSS Inc., Chicago, IL).

\subsection{Selection of Nurse-Practice Setting and Data Collection}

The subjects of the survey were 644 professional nurses practicing at 116 psychiatric hospitals in Japan. These hospitals were stand-alone or single service hospitals with 200 beds or more. In addition, subjects had to work in psychiatric units for at least three years and the clinical experience of more than 5 years of nursing (excluding licensed practical nurse). Since the desire was to extract the specific features of psychiatric nursing in Japan, psychiatric units in general hospitals were excluded.

Initial contact with the managers of the psychiatric hospitals was done to enhance cooperation to participate with the survey. Once commitment was obtained from the managers, the password for the PsyNACS ${ }^{\odot}$ on-line internet-based survey questionnaire was provided to them. The on-line questionnaire package contained the following items: The PsyNACS ${ }^{\odot}$ Questionnaire, and the Demographic Data Sheet. The Demographic Data sheet required respondents to provide their personal data, e.g. age, gender, place of work, years of experience as a nurse in general and years of experience in Psychiatric Units, etc.

The time frame was from February 2015 to April 2015. Follow-up telephone calls to the managers were made to ensure timely access and completion of the questionnaire and to enhance the return rate. The survey was conducted by SurveyMonkey ${ }^{\odot}$.

\subsection{Ethical Considerations}

The University of Tokushima Hospital Clinical Study Ethical Review Board approved this study. No harm to the subjects could be identified. Return of the survey implied that the subjects gave consent. The subjects were notified that privacy would be protected; only aggregate data would be used in reporting the findings.

\section{Results}

\subsection{Characteristics of Respondents}

Of the selected hospitals with 200 or more beds, 116 nursing hospital directors were invited to approve this survey and distribute to their staff. As a result, the questionnaire was accessed by 644 Japanese psychiatric nurses, 
of which 435 (67.5\%) were received with valid answers. The respondents' ages, clinical experiences as a nurse, experience in psychiatric nursing, type of ward functions, and hospital bed size are shown in Table 1.

\subsection{Factor Analysis and the Excluded Items of Each CAD}

As a result of the factor analysis, 31 factors (that is CADs) were extracted to comprise nine PADs. Their alpha factors were in the range of 0.858 to 0.979 . This showed that the over-all data obtained high internal consistency for each factor. The KMO sample adequacy was in the range of 0.86 - 0.96 and the Bartlett's test of sphericity was $\mathrm{p}<0.001$; therefore, this instrument was reliable.

The following CADs were extracted: (PAD1) Five CADs: Psychological symptom (17 items), Stress coping (7 items), Mood disorder and aggression (7 items), Cognition function (4 items), and Delirium and derangement capacity to register failure (3 items); (PAD2) Four CADs: Information of adherence (7 items), Nourishment management (5 items), Blood test (3 items), and Information of the psychiatry rehabilitation (4 items); (PAD3) Four CADs: Eating cognition (11 items), Function of eating (8 items), Excretion situation (5 items), and Balance of water (3 items); (PAD4) Two CADs: Intention/point of view (9 items), and Thoughts of the patient (3 items) were extracted; (PAD5) Five CADs: General health condition (10 items), Sensory organ (4 items), Respiratory and chest symptom (6 items), Vital signs (4 items), and Seeing and hearing (3 items); (PAD6) Three CADs: Egestion and cleanliness (7 items), Activities of daily living (ADL) (6 items), and Appearance (5 items); (PAD7) Four CADs: Situation of the family and social life (7 items), Relationship to the health care provider (5 items), Disease and family (3 items), and Relationships with others (3 items); (PAD8) Two CADs: Activity and sleeping (9 items), and Mobility capability (9 items); and (PAD9) Two CADs: Interest toward sexuality (6 items), and Sexual function (4 items).

Following the factor analysis the following items were excluded: (PAD1) seven items of Incoherence, Circumstantiality of thinking, Perseveration, Trance, Allotriophagy, Factors relating to stress becoming stronger, and Conscious level; (PAD2) Two items of Family history, and Infectious disease; (PAD3) Two items of Thought toward excretion, and Amount of perspiration; (PAD4) Three items of Religious faith, Characteristic, and Kinds of plays and recreations, (PAD5) Two items of Painkiller, and Daily health management; (PAD6) Two items of Degree of satisfaction for clothes, and Feeling of cleanliness; (PAD7) Two items of Address, and Social resources; (PAD8) Four items of Tension of muscles, Muscle strength, Amount of exercise, and Way to

Table 1. Demographic data $(\mathrm{N}=435)$.

\begin{tabular}{|c|c|c|c|c|}
\hline Personal data & Mean & SD & Min & Max \\
\hline Age & 44.55 & 7.50 & 26 & 62 \\
\hline Clinical experience as nurse & 20.40 & 8.20 & 5 & 47 \\
\hline Clinical experience in psychiatry nursing & 17.08 & 8.01 & 3 & 47 \\
\hline The types of ward functions & & & $\mathrm{n}$ & $\%$ \\
\hline Psychiatric acute care unit & & & 109 & 25.06 \\
\hline Psychiatric general care unit & & & 75 & 17.24 \\
\hline Psychiatric long term care unit & & & 134 & 30.80 \\
\hline Complicated disease care unit & & & 51 & 11.72 \\
\hline Dementia care unit & & & 66 & 15.17 \\
\hline Participated hospitals and number of beds & & & $\mathrm{n}$ & $\%$ \\
\hline \multicolumn{5}{|l|}{ Total (59 hospitals) } \\
\hline Over 500 beds & & & 8 & 13.56 \\
\hline 400 - 499 beds & & & 24 & 40.68 \\
\hline 300 - 399 beds & & & 25 & 42.37 \\
\hline 200 - 299 beds & & & 2 & 3.39 \\
\hline
\end{tabular}

$\mathrm{SD}=$ Standard Deviation, Min = Minimum, Max $=$ Maximum. 
spend a day. However, in the (PAD9) assessment item was not excluded (Table 2).

\subsection{Evaluation Results of Important Level of Each CAD}

Considering the factor loading score criteria, the factors with average scores evaluated as " 3 or more than 3 points-importance" were identified.

There were 21 CADs: (PAD1) Psychological symptom (3.15 \pm 0.50, 95\% CI 3.11 - 3.20), Stress coping (3.38 \pm 0.45, 95\% CI 3.34 - 3.42), Mood disorder and aggression (3.47 \pm 0.45 , 95\% CI 3.43 - 3.51), Cognition function (3.22 \pm 0.51 , 95\% CI 3.17 - 3.26), Delirium and derangement capacity to register failure (3.40 $\pm 0.46,95 \%$ CI 3.35 - 3.44); (PAD2) Information of adherence (3.39 \pm 0.36 , 95\% CI 3.36 - 3.42), Information of the psychiatry rehabilitation (3.21 \pm 0.41 , 95\% CI 3.18 - 3.25); (PAD3) Function of eating (3.31 \pm 0.39 , 95\% CI 3.27 - 3.35), Excretion situation (3.02 $\pm 0.41,95 \%$ CI 2.98 - 3.06), Balance of water (3.26 \pm 0.48 , 95\% CI $3.22-3.31$ ); (PAD4) Intention/point of view (3.06 $\pm 0.42,95 \%$ CI $3.02-3.10)$, Thoughts of the patient $(3.29 \pm 0.52,95 \%$ CI 3.24 - 3.34); (PAD5) General health condition (3.18 \pm 0.39 , 95\% CI 3.15 - 3.22), Vital signs (3.12 \pm 0.43 , 95\% CI 3.07 - 3.16); (PAD6) Egestion and cleanliness (3.12 \pm 0.36 , 95\% CI 3.08 - 3.15); (PAD7) Situation of the family and social life (3.11 $\pm 0.43,95 \%$ CI 3.07 - 3.15), Relationship to the health care providers (3.19 \pm 0.46 , 95\% CI 3.14 - 3.23), Disease and family (3.40 \pm 0.44 , 95\% CI 3.36 - 3.45), Relationships with others (3.30 \pm 0.47, 95\% CI 3.26 - 3.35); (PAD8) Activity and sleeping (3.24 \pm 0.40, 95\% CI 3.20 - 3.28) and Mobility capability (3.17 $\pm 0.39,95 \%$ CI $3.14-3.21)$.

However, other CADs were evaluated as "not very important" (Table 3).

\section{Discussion}

This study reflected the responses of professional and experienced nurses who are skilled in psychiatric nursing care in Japan. This raised the level of accuracy of the results of the research. Sampling was considered appropriate, and the number of responses were critical statistically satisfactory. This raised the level of accuracy of the results of the research.

The results of the study demonstrated the degree of importance that the assessment data items of the Psy$\mathrm{NACS}^{\odot}$ serve to distinguish the needs of patients in psychiatric care. These levels provided ways to categorize the Patient Assessment Data (PAD), and the Cluster Assessment Data (CAD). Factor loadings of "4 or more" signifying importance of the items facilitated the development of the PsyNACS ${ }^{\complement}$.

Thirty one CADs were extracted in this research. However, twenty seven items were excluded based on results of factor analysis. For example, allotriophagy of psychological symptoms was one of the assessment data items excluded because this was a problem with autism and/or intellectual disability [23]. Furthermore, other items which are included in the rehabilitation care situations provided by occupational therapists were also excluded. Family support evaluation item is a psychiatric item in which social workers can often intervene. These items were also excluded because these are functions which are performed by other health care professionals. Items related to religion were considered cultural characteristics of Japanese people who are unlikely to have strong religious affiliations and were also excluded.

In PAD1, all of the factors were rated as "important". Mood disorders and dementia are increasing in Japan. The evidence is supported by increased patient admissions in psychiatric hospitals [24]. The numbers of patients admitted to the psychiatric hospitals are about 29 million patients, most often due to schizophrenia [25]. In particular, facilitation of adaptive coping with serious mental illnesses is an important part of psychiatric-mental health nursing care [26].

In PAD2, regarding Information about treatments, Information of adherence, and Information about psychiatric rehabilitation were all rated as "important". According to Bowers [27], the roles of the nurse is to provide safety for patient and others, collect valuable information about patients, monitor treatment efficacies, manage disturbed behavior, provide personal care, and manage a comfortable environment for patients. Therefore, it is considered important to patient care success that nurses acquire crucial information concerning the patient's ability to understand, the developmental stage, and treatments performed. This is particularly critical to psychiatric patients who may have relapsing condition of the psychiatric disease.

Nourishment management, and blood tests were assessment data which were evaluated as "not very important”. However, blood test is included because of the average value which was in the range of $2.93-3.0295 \%$ CI. These assessment data are physiological information that may have value that is vital to the patient's health condition. 
Table 2. (a) Result of factor analysis (PAD 1-2); (b) Result of factor analysis (PAD 3-4); (c) Result of factor analysis (PAD 5-6); (d) Result of factor analysis (PAD 7-9).

(a)

\begin{tabular}{|c|c|c|c|c|c|c|c|c|c|c|}
\hline $\begin{array}{l}\text { PAD1 Psychological } \\
\text { symptom and stress } \\
\qquad(\alpha=0.979)\end{array}$ & CAD1 & CAD2 & CAD3 & CAD4 & CAD5 & $\begin{array}{l}\text { PAD2 Information about } \\
\text { treatment }(\alpha=0.858)\end{array}$ & CAD1 & CAD2 & CAD3 & CAD4 \\
\hline
\end{tabular}

CAD1 Psychological

symptom $(\alpha=0.975)$

\begin{tabular}{|c|c|c|c|c|c|}
\hline Thought blocking & 0.851 & 0.200 & 0.173 & 0.201 & 0.256 \\
\hline Dominant theme & 0.842 & 0.189 & 0.178 & 0.223 & 0.143 \\
\hline $\begin{array}{c}\text { Tought } \\
\text { broadcasting }\end{array}$ & 0.838 & 0.189 & 0.212 & 0.137 & 0.240 \\
\hline Inhibition of ideas & 0.831 & 0.211 & 0.178 & 0.182 & 0.290 \\
\hline Delusion of control & 0.829 & 0.214 & 0.189 & 0.190 & 0.120 \\
\hline Flight of ideas & 0.795 & 0.219 & 0.189 & 0.184 & 0.310 \\
\hline Compulsive thought & 0.789 & 0.223 & 0.254 & 0.177 & 0.217 \\
\hline Depersonalization & 0.780 & 0.200 & 0.262 & 0.222 & -0.010 \\
\hline Incoherent thought & 0.746 & 0.241 & 0.260 & 0.122 & 0.336 \\
\hline Multiple personality & 0.714 & 0.203 & 0.216 & 0.232 & -0.040 \\
\hline Ambivalence & 0.704 & 0.277 & 0.107 & 0.337 & 0.012 \\
\hline $\begin{array}{c}\text { Personality } \\
\text { characteristics }\end{array}$ & 0.611 & 0.229 & 0.330 & 0.249 & 0.150 \\
\hline Apathy & 0.604 & 0.334 & 0.282 & 0.353 & 0.194 \\
\hline $\begin{array}{c}\text { Affective } \\
\text { emotional } \\
\text { incontinence }\end{array}$ & 0.536 & 0.353 & 0.230 & 0.398 & 0.200 \\
\hline Hypobulia & 0.514 & 0.391 & 0.193 & 0.420 & 0.202 \\
\hline Illusion & 0.488 & 0.138 & 0.090 & 0.293 & 0.307 \\
\hline Fear & 0.469 & 0.384 & 0.276 & 0.404 & 0.141 \\
\hline
\end{tabular}

\section{CAD2 Stress coping}

$(\alpha=0.928)$

\section{CAD1 Information of}

adherence $(\alpha=0.783)$

\section{Knowledge of the disease \\ Comprehension of things \\ Information on the \\ internal medicine}

History of present illness

Consultation and therapeutic situation

Developmental stage

Medical history of the person

Intellectual disability

CAD2 Nutritional management $(\alpha=0.786)$

Weight

Body mass index (BMI)

Smoking history

Drinking history

CAD3 Blood test $(\alpha=0.784)$

$$
\begin{gathered}
\text { Blood general } \\
\text { inspection(RBC/WBC) } \\
\text { Serum chemistry } \\
\text { (TP/Alb/TG/Liver } \\
\text { function/Electrolyte) } \\
\\
\text { Blood clotting } \\
\text { test (PT/APTT) }
\end{gathered}
$$

CAD4 Information of Psychiatry rehabilitation $(\alpha=0.570)$

\begin{tabular}{|l|lll}
\hline 0.663 & 0.052 & -0.012 & 0.053 \\
0.608 & 0.057 & 0.002 & 0.192 \\
0.567 & 0.148 & 0.159 & 0.087 \\
& & & \\
0.540 & 0.074 & 0.252 & 0.119 \\
& & & \\
0.539 & 0.217 & -0.013 & 0.214 \\
0.428 & 0.234 & 0.179 & 0.069 \\
0.427 & 0.148 & 0.001 & 0.385 \\
\hline
\end{tabular}

\begin{tabular}{l|l|ll}
0.083 & 0.718 & 0.168 & 0.165 \\
0.085 & 0.698 & 0.165 & 0.104 \\
0.121 & 0.592 & 0.231 & 0.194 \\
0.216 & 0.585 & 0.091 & 0.070 \\
0.342 & 0.436 & 0.133 & 0.087
\end{tabular}

\begin{tabular}{ll|l|l}
0.105 & 0.194 & 0.904 & 0.088 \\
& & & \\
0.186 & 0.255 & 0.709 & 0.201 \\
& & & \\
0.053 & 0.309 & 0.475 & 0.172 \\
& & &
\end{tabular}




\section{Continued}

\begin{tabular}{|c|c|c|c|c|c|c|c|c|c|c|}
\hline $\begin{array}{l}\text { Psychological } \\
\text { stress }\end{array}$ & 0.248 & 0.765 & 0.230 & 0.149 & 0.232 & Communication disorder & 0.324 & 0.026 & 0.025 & 0.526 \\
\hline Causes of stress & 0.224 & 0.741 & 0.292 & 0.139 & 0.174 & $\begin{array}{l}\text { The contents of } \\
\text { rehabilitation }\end{array}$ & -0.005 & 0.165 & 0.202 & 0.507 \\
\hline $\begin{array}{l}\text { Psychological } \\
\text { pain }\end{array}$ & 0.299 & 0.733 & 0.282 & 0.201 & 0.170 & Recent weight change & 0.134 & 0.151 & 0.131 & 0.505 \\
\hline $\begin{array}{l}\text { Environmental } \\
\text { Stressor }\end{array}$ & 0.150 & 0.715 & 0.182 & 0.188 & 0.215 & $\begin{array}{l}\text { Ingestion usage of drugs and } \\
\text { addictive substances }\end{array}$ & 0.375 & 0.127 & 0.094 & 0.451 \\
\hline $\begin{array}{l}\text { Life Event } \\
\text { Stressor }\end{array}$ & 0.266 & 0.652 & 0.217 & 0.196 & 0.065 & & & & & \\
\hline Coping skills & 0.297 & 0.623 & 0.277 & 0.194 & 0.033 & Contributing rate (\%) & 13.60 & 12.15 & 9.84 & 7.47 \\
\hline Anxiety & 0.344 & 0.428 & 0.335 & 0.310 & 0.324 & $\begin{array}{c}\text { Cumulative contribution } \\
\text { ratio (\%) }\end{array}$ & & 25.75 & 35.59 & 43.06 \\
\hline
\end{tabular}

CAD3 Mood disorder and aggression $(\alpha=0.939)$

\begin{tabular}{ccc|c|cc}
$\begin{array}{c}\text { Harming (others } \\
\text { and/or oneself) }\end{array}$ & 0.181 & 0.279 & 0.773 & 0.162 & 0.068 \\
$\begin{array}{c}\text { Assaultive } \\
\text { behavior }\end{array}$ & 0.196 & 0.321 & 0.758 & 0.175 & 0.076 \\
Excitement & 0.250 & 0.253 & 0.732 & 0.188 & 0.311 \\
Irritability & 0.299 & 0.295 & 0.646 & 0.189 & 0.277 \\
Manic behavior & 0.450 & 0.278 & 0.588 & 0.149 & 0.319 \\
Delusion & 0.318 & 0.244 & 0.553 & 0.107 & 0.441 \\
Depressed mood & 0.415 & 0.293 & 0.528 & 0.198 & 0.293
\end{tabular}

CAD4 Cognition

function $(\alpha=0.931)$

\begin{tabular}{cccc|c|c} 
Agnosia & 0.337 & 0.231 & 0.211 & 0.786 & 0.197 \\
Apraxia & 0.393 & 0.240 & 0.190 & 0.770 & 0.183 \\
Aphasia & 0.345 & 0.254 & 0.171 & 0.751 & 0.120 \\
Loitering & 0.276 & 0.242 & 0.237 & 0.526 & 0.359
\end{tabular}

CAD5 Delirium and derangement capacity to register failure $(\alpha=0.830)$

\begin{tabular}{|c|c|c|c|c|c|}
\hline Delirium & 0.204 & 0.210 & 0.272 & 0.206 & 0.622 \\
\hline $\begin{array}{l}\text { Derangement } \\
\text { capacity to } \\
\text { register failure }\end{array}$ & 0.210 & 0.220 & 0.217 & 0.301 & 0.589 \\
\hline Hallucination & 0.399 & 0.239 & 0.368 & 0.110 & 0.560 \\
\hline Contributing rate (\%) & 27.88 & 13.79 & 12.62 & 10.35 & 7.51 \\
\hline $\begin{array}{c}\text { Cumulative } \\
\text { contribution ratio (\%) }\end{array}$ & & 41.68 & 54.30 & 64.65 & 72.16 \\
\hline
\end{tabular}

KMO = 0.96; Bartlett's test of sphericity $=19,139.37, \mathrm{p}<0.001$, Principal factor analisis (Varimax rotation). PAD: Patient Assessment Data. CAD: Cluster Assessment Data. KMO: Kaisar-Meyer-Olkin test. 
(b)

\begin{tabular}{|c|c|c|c|c|c|c|c|}
\hline $\begin{array}{l}\text { PAD3 Function of eating and } \\
\text { balance of water }(\alpha=0.940)\end{array}$ & CAD1 & CAD2 & CAD3 & CAD4 & PAD4 Life and value $(\alpha=0.922)$ & CAD1 & CAD2 \\
\hline $\begin{array}{c}\text { CAD1 Eating cognition } \\
(\alpha=0.893)\end{array}$ & & & & & \multicolumn{2}{|c|}{ CAD1 Intention/point of view ( $\alpha=0.897)$} & \\
\hline Sense of hunger & 0.712 & 0.205 & 0.133 & 0.107 & Self expectation & 0.729 & 0.285 \\
\hline $\begin{array}{l}\text { Sense of abdominal } \\
\text { fullness }\end{array}$ & 0.670 & 0.240 & 0.225 & 0.101 & Ethical thought & 0.693 & 0.232 \\
\hline $\begin{array}{l}\text { Change of dietary } \\
\text { habits }\end{array}$ & 0.651 & 0.183 & 0.263 & 0.104 & Patient's strength & 0.662 & 0.364 \\
\hline $\begin{array}{c}\text { Intake of } \\
\text { between-meal eating }\end{array}$ & 0.636 & 0.172 & 0.144 & 0.070 & Hope & 0.658 & 0.403 \\
\hline Number of meals & 0.635 & 0.106 & 0.362 & -0.044 & Motivation & 0.603 & 0.316 \\
\hline Mealtime & 0.630 & 0.171 & 0.389 & -0.016 & Purpose of life & 0.602 & 0.463 \\
\hline Preference & 0.624 & 0.221 & 0.284 & 0.067 & Goal of life & 0.601 & 0.398 \\
\hline Body Image & 0.622 & 0.023 & 0.040 & 0.228 & $\begin{array}{l}\text { Participation of the nursing } \\
\text { care plan }\end{array}$ & 0.573 & 0.170 \\
\hline $\begin{array}{c}\text { The presence or } \\
\text { absence of overeating }\end{array}$ & 0.549 & 0.105 & 0.151 & 0.393 & $\begin{array}{c}\text { Important belief except } \\
\text { the religion }\end{array}$ & 0.528 & 0.285 \\
\hline Understanding of diet & 0.459 & 0.170 & 0.097 & 0.336 & \multicolumn{2}{|l|}{$\begin{array}{l}\text { CAD2 Thoughts of the patient } \\
\qquad(\alpha=\mathbf{0 . 8 8 6})\end{array}$} & \\
\hline Eating action & 0.434 & 0.353 & 0.246 & 0.241 & Current thought of the patient & 0.296 & 0.918 \\
\hline $\begin{array}{l}\text { CAD2 Function of eating } \\
\qquad(\alpha=0.890)\end{array}$ & & & & & \multirow{3}{*}{$\begin{array}{l}\text { Future thought of the patient } \\
\text { Thought of the patient before } \\
\text { the illness }\end{array}$} & 0.340 & 0.841 \\
\hline Swallowing function & 0.099 & 0.868 & 0.071 & 0.158 & & 0.438 & 0.572 \\
\hline Mastication & 0.218 & 0.737 & 0.203 & 0.054 & & & \\
\hline $\begin{array}{l}\text { Presence or absence } \\
\text { of aspiration }\end{array}$ & 0.074 & 0.680 & 0.100 & 0.217 & Contributing rate (\%) & 33.11 & 24.07 \\
\hline Oral conditions & 0.344 & 0.592 & 0.279 & 0.054 & $\begin{array}{c}\text { Cumulative contribution } \\
\text { ratio (\%) }\end{array}$ & & 57.19 \\
\hline Signs of dehydration & 0.182 & 0.575 & 0.232 & 0.292 & \multirow{16}{*}{\multicolumn{3}{|c|}{$\mathrm{KMO}=0.91 ;$ Bartlett's test of sphericity $=3256.43, \mathrm{p}<0.001$}} \\
\hline Fluid intake & 0.182 & 0.515 & 0.314 & 0.334 & & & \\
\hline Dietary intake & 0.271 & 0.508 & 0.363 & 0.052 & & & \\
\hline $\begin{array}{l}\text { Presence or absence } \\
\text { of dentures and } \\
\text { condition of use }\end{array}$ & 0.323 & 0.437 & 0.313 & 0.084 & & & \\
\hline \multicolumn{4}{|l|}{$\begin{array}{l}\text { CAD3 Excretion situation } \\
\qquad(\alpha=0.857)\end{array}$} & & & & \\
\hline $\begin{array}{c}\text { Symptom at having } \\
\text { egested }\end{array}$ & 0.392 & 0.222 & 0.702 & 0.107 & & & \\
\hline Property of egesta & 0.298 & 0.325 & 0.661 & 0.113 & & & \\
\hline Frequency of urination & 0.360 & 0.310 & 0.535 & 0.105 & & & \\
\hline $\begin{array}{l}\text { Frequency of urination } \\
\text { during night }\end{array}$ & 0.428 & 0.259 & 0.479 & 0.103 & & & \\
\hline Frequency of stool & 0.149 & 0.430 & 0.454 & 0.256 & & & \\
\hline \multicolumn{5}{|l|}{$\begin{array}{l}\text { CAD4 Balance of water } \\
\qquad(\alpha=0.837)\end{array}$} & & & \\
\hline $\begin{array}{c}\text { History of water } \\
\text { intoxication }\end{array}$ & 0.122 & 0.190 & 0.061 & 0.872 & & & \\
\hline Polyposia & 0.107 & 0.227 & 0.067 & 0.841 & & & \\
\hline Excessive urination & 0.351 & 0.311 & 0.323 & 0.447 & & & \\
\hline Contributing rate (\%) & 19.31 & 15.77 & 10.73 & 9.21 & & & \\
\hline $\begin{array}{c}\text { Cumulative } \\
\text { contribution ratio (\%) }\end{array}$ & & 35.08 & 45.81 & 55.02 & & & \\
\hline
\end{tabular}

KMO = 0.93; Bartlett's test of sphericity $=7182.11, \mathrm{p}<0.01$, Principal factor analisis (Varimax rotation). PAD: Patient Assessment Data. CAD: Cluster Assessment Data. KMO: Kaisar-Meyer-Olkin test. 
(c)

\begin{tabular}{|c|c|c|c|c|c|c|c|c|c|}
\hline $\begin{array}{l}\text { PAD5 Vital signs and } \\
\text { health assessment } \\
(\alpha=0.906)\end{array}$ & CAD1 & CAD2 & CAD3 & CAD4 & CAD5 & $\begin{array}{l}\text { PAD6 Self-care } \\
\quad(\alpha=0.915)\end{array}$ & CAD1 & CAD2 & CAD3 \\
\hline $\begin{array}{l}\text { CAD1 General health } \\
\text { condition }(\alpha=0.906)\end{array}$ & & & & & & $\begin{array}{l}\text { CAD1 Egestion and } \\
\text { cleanliness }(\alpha=0.863)\end{array}$ & & & \\
\hline $\begin{array}{l}\text { Presence or absence of } \\
\text { nausea and vomiting }\end{array}$ & 0.776 & 0.097 & 0.211 & 0.112 & 0.100 & Egestion & 0.789 & 0.081 & 0.102 \\
\hline Ileus & 0.698 & -0.008 & 0.144 & 0.060 & -0.007 & Picking up after having egested & 0.766 & 0.177 & 0.107 \\
\hline Abdominal condition & 0.677 & 0.117 & 0.116 & 0.198 & 0.090 & Coprophilia & 0.688 & 0.073 & 0.198 \\
\hline Sign of infection & 0.650 & 0.055 & 0.200 & 0.210 & 0.085 & $\begin{array}{l}\text { Independence of the clothes } \\
\text { of the detachable }\end{array}$ & 0.656 & 0.265 & 0.279 \\
\hline Tracheal secretion & 0.640 & 0.260 & 0.362 & 0.079 & 0.131 & $\begin{array}{c}\text { Independence of } \\
\text { the cleanliness }\end{array}$ & 0.572 & 0.284 & 0.293 \\
\hline Edema & 0.632 & 0.214 & 0.187 & 0.219 & 0.095 & Habits of the cleanliness & 0.499 & 0.230 & 0.374 \\
\hline Aching pain & 0.605 & 0.347 & 0.151 & 0.318 & 0.136 & Situation of oral care & 0.458 & 0.082 & 0.316 \\
\hline Condition of skin & 0.552 & 0.387 & 0.059 & 0.300 & 0.092 & $\begin{array}{l}\text { CAD2 Activities of daily } \\
\text { living (ADL) }(\alpha=\mathbf{0 . 8 8 6})\end{array}$ & & & \\
\hline Symptoms of allergy & 0.531 & 0.073 & 0.155 & 0.256 & 0.204 & $\begin{array}{l}\text { Performs housework } \\
\text { independently }\end{array}$ & 0.217 & 0.897 & 0.173 \\
\hline Sense of fatigue & 0.416 & 0.404 & 0.104 & 0.197 & 0.148 & $\begin{array}{l}\text { Performs cooking } \\
\text { independently }\end{array}$ & 0.137 & 0.818 & 0.248 \\
\hline $\begin{array}{l}\text { CAD2 Sensory organ } \\
\qquad(\alpha=0.870)\end{array}$ & & & & & & Shops independently & 0.204 & 0.814 & 0.221 \\
\hline Sense of smell & 0.092 & 0.773 & 0.222 & 0.070 & 0.218 & Wash clothes independently & 0.174 & 0.596 & 0.300 \\
\hline Sense of taste & 0.112 & 0.744 & 0.195 & 0.059 & 0.261 & Wears makeup & 0.055 & 0.498 & 0.433 \\
\hline Sense of touch & 0.186 & 0.736 & 0.232 & 0.080 & 0.290 & Prepares meals independently & 0.408 & 0.431 & 0.207 \\
\hline Itching sensation & 0.517 & 0.534 & 0.091 & 0.168 & 0.095 & $\begin{array}{c}\text { CAD3 Appearance } \\
(\alpha=0.822)\end{array}$ & & & \\
\hline $\begin{array}{l}\text { CAD3 Respiratory and } \\
\text { chest symptom } \\
(\alpha=0.912)\end{array}$ & & & & & & $\begin{array}{l}\text { Clothes are approriate } \\
\text { for the season }\end{array}$ & 0.207 & 0.263 & 0.687 \\
\hline Oxygen saturation & 0.295 & 0.162 & 0.717 & 0.278 & 0.172 & Hair styling & 0.145 & 0.283 & 0.644 \\
\hline Breath sounds & 0.252 & 0.270 & 0.686 & 0.257 & 0.168 & $\begin{array}{l}\text { Number of times } \\
\text { of having baths }\end{array}$ & 0.256 & 0.215 & 0.598 \\
\hline $\begin{array}{c}\text { Presence or absence of } \\
\text { cyanosis }\end{array}$ & 0.399 & 0.124 & 0.654 & 0.211 & 0.114 & $\begin{array}{l}\text { Body temperature } \\
\text { adjustment by clothes }\end{array}$ & 0.362 & 0.146 & 0.575 \\
\hline Respiratory rhythm & 0.156 & 0.368 & 0.605 & 0.381 & 0.134 & Appearance & 0.348 & 0.320 & 0.560 \\
\hline Respiratory rate & 0.427 & 0.212 & 0.523 & 0.255 & 0.184 & & & & \\
\hline Chest symptom & 0.124 & 0.377 & 0.501 & 0.442 & 0.148 & & & & \\
\hline $\begin{array}{l}\text { CAD4 Vital signs } \\
\qquad(\alpha=0.885)\end{array}$ & & & & & & Contributing rate (\%) & 19.93 & 19.45 & 15.62 \\
\hline Pulse rate & 0.209 & 0.213 & 0.220 & 0.781 & 0.133 & $\begin{array}{c}\text { Cumulative } \\
\text { contribution ratio (\%) } \\
\end{array}$ & & 39.38 & 55.00 \\
\hline Body temperature & 0.318 & 0.084 & 0.259 & 0.725 & 0.092 & \multicolumn{4}{|c|}{$\mathrm{KMO}=0.91 ;$ Bartlett's test of sphericity $=4469.32, \mathrm{p}<0.001$} \\
\hline Blood pressure & 0.308 & 0.018 & 0.309 & 0.684 & 0.134 & & & & \\
\hline Abnormal cardiac rhythm & 0.364 & 0.076 & 0.273 & 0.535 & 0.195 & & & & \\
\hline \multicolumn{10}{|l|}{$\begin{array}{c}\text { CAD5 Sense of } \\
\text { hearing, Visual acuity } \\
(\alpha=0.873)\end{array}$} \\
\hline Sense of hearing & 0.151 & 0.333 & 0.225 & 0.128 & 0.823 & & & & \\
\hline Visual acuity & 0.132 & 0.392 & 0.263 & 0.206 & 0.656 & & & & \\
\hline $\begin{array}{l}\text { Use of glasses and } \\
\text { hearing aid }\end{array}$ & 0.201 & 0.378 & 0.079 & 0.189 & 0.590 & & & & \\
\hline Contributing rate (\%) & 19.30 & 12.81 & 11.89 & 11.37 & 7.53 & & & & \\
\hline $\begin{array}{c}\text { Cumulative } \\
\text { contribution ratio (\%) }\end{array}$ & & 32.12 & 44.01 & 55.38 & 62.91 & & & & \\
\hline
\end{tabular}

KMO = 0.94; Bartlett's test of sphericity $=8441.42, \mathrm{p}<0.01$, Principal factor analisis (Varimax rotation). PAD: Patient Assessment Data. CAD: Cluster Assessment Data. KMO: Kaisar-Meyer-Olkin test. 
(d)

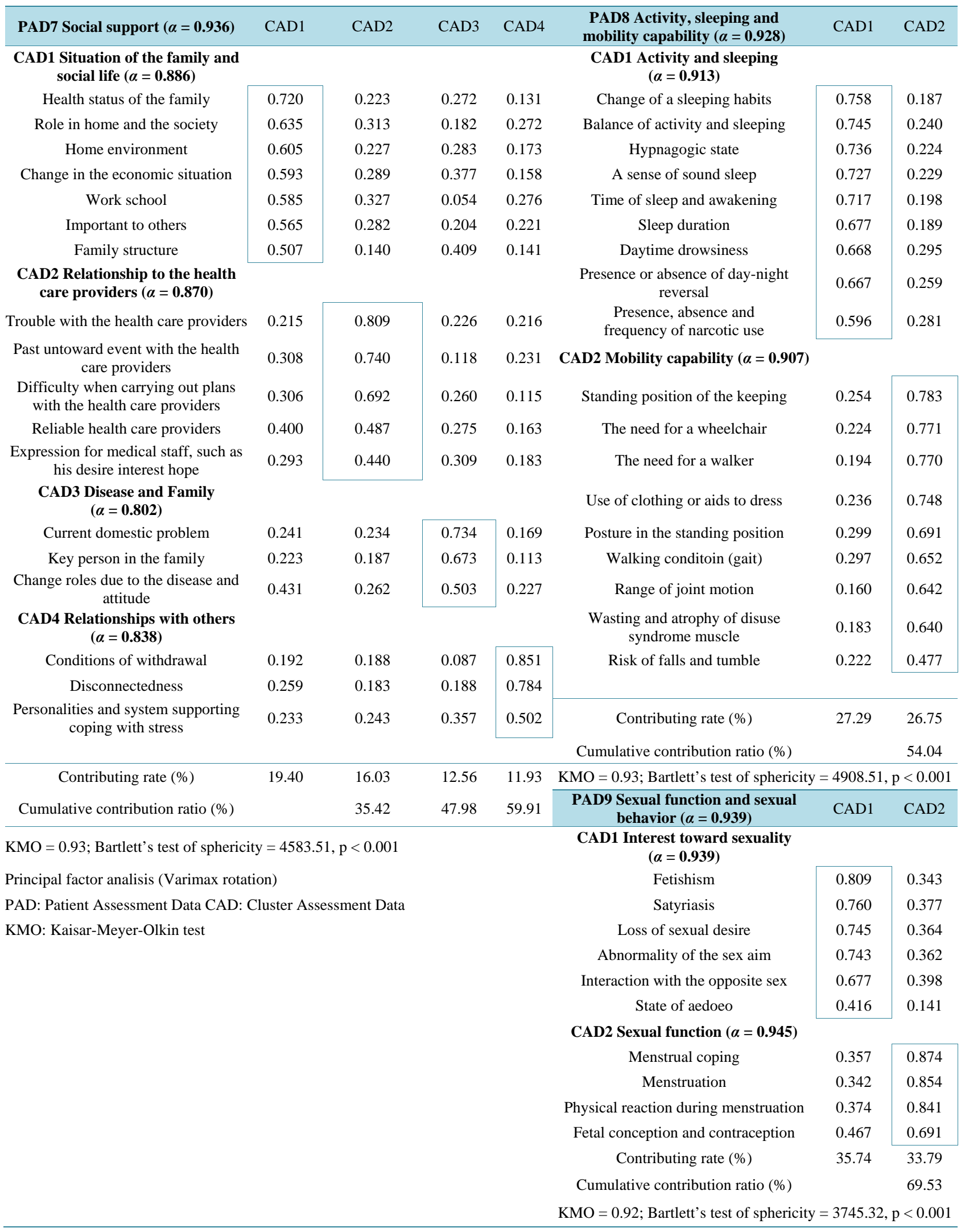


Table 3. Descriptive statistics results of each CAD.

\begin{tabular}{|c|c|c|c|c|c|c|c|}
\hline \multirow[b]{2}{*}{ PAD } & \multicolumn{6}{|c|}{ MFP } & \\
\hline & & & Min & Max & Mean & SD & $95 \%$ CI \\
\hline \multirow{5}{*}{ PAD1 } & CAD1 & Psychological symptom & 1.94 & 4.00 & 3.15 & 0.50 & $3.11-3.20$ \\
\hline & CAD2 & Stress coping & 2.00 & 4.00 & 3.38 & 0.45 & $3.34-3.42$ \\
\hline & CAD3 & Mood disorder and aggression & 2.00 & 4.00 & 3.47 & 0.45 & $3.43-3.51$ \\
\hline & CAD4 & Cognition function & 1.50 & 4.00 & 3.22 & 0.51 & $3.17-3.26$ \\
\hline & CAD5 & $\begin{array}{l}\text { Delirium and derangement capacity to } \\
\text { register failure }\end{array}$ & 2.00 & 4.00 & 3.40 & 0.46 & $3.35-3.44$ \\
\hline \multirow{4}{*}{ PAD2 } & CAD1 & Information of adherence & 2.29 & 4.00 & 3.39 & 0.36 & $3.36-3.42$ \\
\hline & CAD2 & Nourishment management & 1.60 & 4.00 & 2.77 & 0.44 & $2.73-2.81$ \\
\hline & CAD3 & Blood test & 1.33 & 4.00 & 2.97 & 0.48 & $2.93-3.02$ \\
\hline & CAD4 & Information of the psychiatry rehabilitation & 1.75 & 4.00 & 3.21 & 0.41 & $3.18-3.25$ \\
\hline \multirow{4}{*}{ PAD3 } & CAD1 & Eating cognition & 1.82 & 4.00 & 2.87 & 0.39 & $2.83-2.90$ \\
\hline & CAD2 & Function of eating & 2.25 & 4.00 & 3.31 & 0.39 & $3.27-3.35$ \\
\hline & CAD3 & Excretion situation & 1.80 & 4.00 & 3.02 & 0.41 & $2.98-3.06$ \\
\hline & CAD4 & Balance of water & 2.00 & 4.00 & 3.26 & 0.48 & $3.22-3.31$ \\
\hline \multirow{2}{*}{ PAD4 } & CAD1 & Intention/Point of view & 1.33 & 4.00 & 3.06 & 0.42 & $3.02-3.10$ \\
\hline & CAD2 & Thoughts of the patient & 1.00 & 4.00 & 3.29 & 0.52 & $3.24-3.34$ \\
\hline \multirow{5}{*}{ PAD5 } & CAD1 & General health condition & 2.00 & 4.00 & 3.18 & 0.39 & $3.15-3.22$ \\
\hline & CAD2 & Sensory organ & 1.25 & 4.00 & 2.65 & 0.50 & $2.60-2.70$ \\
\hline & CAD3 & Respiratory and chest symptom & 1.00 & 4.00 & 2.87 & 0.51 & $2.82-2.92$ \\
\hline & CAD4 & Vital signs & 1.75 & 4.00 & 3.12 & 0.43 & $3.07-3.16$ \\
\hline & CAD5 & Seeing and hearing & 1.33 & 4.00 & 2.81 & 0.47 & $2.77-2.86$ \\
\hline \multirow{3}{*}{ PAD6 } & CAD1 & Egestion and cleanliness & 2.00 & 4.00 & 3.12 & 0.36 & $3.08-3.15$ \\
\hline & CAD2 & ADL (activity of daily living) & 1.00 & 4.00 & 2.78 & 0.50 & $2.74-2.83$ \\
\hline & CAD3 & Appearance & 1.20 & 4.00 & 2.78 & 0.41 & $2.74-2.81$ \\
\hline \multirow{4}{*}{ PAD7 } & CAD1 & Situation of the family and social life & 1.29 & 4.00 & 3.11 & 0.43 & $3.07-3.15$ \\
\hline & CAD2 & Relationship to the health care providers & 1.40 & 4.00 & 3.19 & 0.46 & $3.14-3.23$ \\
\hline & CAD3 & Disease and family & 2.00 & 4.00 & 3.40 & 0.44 & $3.36-3.45$ \\
\hline & CAD4 & Relationships with others & 2.00 & 4.00 & 3.30 & 0.47 & $3.26-3.35$ \\
\hline \multirow{2}{*}{ PAD8 } & CAD1 & Activity and sleeping & 2.00 & 4.00 & 3.24 & 0.40 & $3.20-3.28$ \\
\hline & CAD2 & Mobility capability & 1.67 & 4.00 & 3.17 & 0.39 & $3.14-3.21$ \\
\hline \multirow{2}{*}{ PAD9 } & CAD1 & Interest toward sexuality & 1.00 & 4.00 & 2.58 & 0.53 & $2.53-2.63$ \\
\hline & CAD2 & Sexual function & 1.00 & 4.00 & 2.66 & 0.72 & $2.59-2.72$ \\
\hline
\end{tabular}

PAD: Psychiatric Assessment Data. CAD: Cluster Assessment Data. MFP: Mean Factor Point. Min: Minimum. Max: Maximum. n.s.: not significant. $\mathrm{SD}=$ Standard Deviation. CI: Confidence Interval.

In PAD3, Function of eating, Excretion situations, and Balance of water were rated as "important". Excretion situation included the items concerning the symptom and personal situations at the time of excretion. This was considered to be an observation item necessary for the assessment of physical symptoms. Disturbance in the balance of fluid intake including water is considered to cause physiological problems that can directly and indirectly influence the whole-body management, and the consequent pharmacological effects of psychoactive drugs 
for long term effects. Balance of water was rated "important” by respondents. However, in Japan, in-patients with schizophrenia accounts for about $60 \%$, while the number of patients with eating disorders are few. This may explain why "Eating cognition" was evaluated as "not very important."

In PAD4, all factors influencing human life were considered valuable, including Intention/point of view, and thoughts of the patient. These were evaluated as important. In a study by Kataoka et al. [28], Japanese nurses' involvement in patient situations included four factors based on the assessment which focused on social resources; holistic assessment, person's way of living, and the strengths of individuals with mental disability. It is considered that, in order to understand patients [29] responses to care involving appreciation of human wholeness occur in a momentary resolution often from their viewpoints on nursing care, and thoughts of the patient as an "important" factor.

In PAD5, assessing Vital signs and General health condition, respondents evaluated these items as 'important'. However, items such as Sensory organ, Respiratory and chest symptom, and Seeing and hearing were evaluated as "not very important". While these are items related to the five senses, visual acuity and sense of hearing, was evaluated as "not very important" as well. This was also observed in the case of Respiratory and chest symptoms, as these were treated efficiently by moving the patient to a ward or hospital which has a physician.

In PAD6, in the area of Self-care, Egestion and cleanliness was evaluated as "very important". ADL and Appearance however, were evaluated as "not very important". The ADL was also evaluated by the capability to be mobile in PAD8. In some cases, a patient with schizophrenia may lose all interest in his or her personal grooming because negative symptoms of schizophrenia, which involve a loss of function, may include lack of motivation, social avoidance, and lack of emotional response [30]. Support for a person's Appearance may be important for social activities. However, for long term hospitalization, this might not be important by the nurses.

In PAD7, Situations of the family and social life, Disease and family, Relationship to the health care provider and Relationship with others were found to be "important". A study by Sawada et al. [31] reported that the roles of psychiatric nursing care as "basic activities of daily living, psychological support/interpersonal skills, medical support, monitoring, family support and miscellaneous" may be required interventions for patients in acute psychiatric hospitals in Japan.

In PAD8, Activity and sleeping and Mobility capability, includes items concerning "Risk of falls and tumble". The risks of tumbling down and falling are not caused by purely psychiatric symptoms. The research by Sano et $a l$. [32] indicated that every antipsychotic pill drug increases the risk of tumbling and falling at the rate of 2.63 times as the result of side effects of internally administered medicines. Stenhagen M. et al. [33] explained that the lowering of Cognition function; and the condition of Instrumental Activities of Daily Living caused by aging are related to the risks of tumbling and falling. In the research by Soderqvist A. et al. [34], assessments of "Cognition function" by nurses were lower than in actual conditions. Psychiatric hospitals in Japan are considered to put emphasis on the risk assessments for tumbling and falling particularly for the advancing population of the aged.

In PAD9, Interest toward sexuality and Sexual function were evaluated as "not very important". Antipsychotic polypharmacy was associated with increased side effect burden, increasing rates of Parkinsonian side effects, anticholinergic symptoms, hyperprolactinemia, sexual dysfunction, hypersalivation, sedation/somnolence, cognitive impairment, and diabetes [35]. Although the events concerning sexuality tends to be considered less serious in the hospital than in the community society, "Interest toward sexuality" was regarded as "important" not only for the young, but also by the elderly; therefore, it is necessary to include "Sexual behavior problems" as a very important assessment data as this condition sometimes occur because of inappropriate judgments owing to the psychiatric symptom in psychiatric wards. According to the research by Steven et al. [36], many of the patients with chronic psychiatric disease were sexually active. Therefore, it is appropriate that PsyNACS ${ }^{\odot}$ include sexual behavior of patients as critical assessment data, recognizing the importance of sexuality human living without ignoring their desire [37].

\section{Limitations}

The researcher used theoretically-based assessment data from selected theoretical sources such as textbooks on nursing theory and models. Furthermore, the survey items had included symptoms and names of diseases in part, and some synonyms. In the PAD9 of Sexual function and sexual behavior, the most asked commonly questions were concerning female sexual behavior and those concerning male sexual activities were few. 


\section{Conclusion}

Assessment items of the PsyNACS ${ }^{\odot}$ were evaluated "important" by professional nurses who practiced in psychiatric hospitals in Japan. Through the dissemination of the PsyNACS with publications in a clinical nursing journal and distribution to staff in psychiatric hospitals, patient care will be improved. The PsyNACS ${ }^{\odot}$ will provide an excellent assessment data classification system specific to Japanese psychiatric health care environment. It can be used for psychiatric nursing care practice, from acute to chronic care; also it can facilitate the implementation of an efficient and practical psychiatric patient care plan.

\section{Acknowledgements}

We would like to express our deep gratitude to the Japanese psychiatric nurses and nursing administrators who participated in this study. And we also would like to express our deep gratitude to the academic supervisors.

\section{References}

[1] The Part of Disorder's Health Welfare, Ministry of Health, Lavour and Welfare (2015) About Health Care Planning (Mental Disease). (In Japanese) http://www.mhlw.go.jp/seisakunitsuite/bunya/kenkou_iryou/iryou/iryou_keikaku/dl/shiryou_a-3.pdf

[2] Organization of Economics and Development (OECD) (2014) Japan Trails Other Countries in 'Deinstitutionalization', But There Are Signs of Progress, Says OECD. http://www.oecd.org/els/health-systems/MMHC-Country-Press-Note-Japan.pdf.

[3] Corrigan, P.W., Green, A., Lundin, R., Kubiak, M.A. and Penn, D.L. (2001) Familiarity with and Social Distance from People Who Have Serious Mental Illness. Psychiatric Services, 52, 953-958. http://dx.doi.org/10.1176/appi.ps.52.7.953

[4] Crisp, A.H., Gelder, M.G., Rix, S., Meltzer, H.I. and Rowlands, O.J. (2000) Stigmatisation of People with Mental Illnesses. The British Journal of Psychiatry, 177, 4-7. http://dx.doi.org/10.1192/bjp.177.1.4

[5] WHO Media Center Fact Sheet No. 352 (2014) Disability and Health. http://www.who.int/mediacentre/factsheets/fs352/en/

[6] Jobe, T.H. and Harrow, M. (2005) Long-Term Outcome of Patients with Schizophrenia, A Review. Canadian Journal of Psychiatry, 50, 892-900.

[7] Gastal, F.L., Andreoli, S.B., Quintana, M.I., Gameiroa, M.A., Leitea, S.O. and McGrathc, J. (2000) Predicting the Revolving Door Phenomenon among Patients with Schizophrenic, Affective Disorders and Non-Organic Psychoses. Revista de Saúde Pública, 34, 280-285. http://dx.doi.org/10.1590/S0034-89102000000300011

[8] Frick, U., Frick, H., Langguth, B., Landgrebe, M., Hübner-Liebermann, B. and Hajak, G. (2013) The Revolving Door Phenomenon Revisited. Time to Readmission in 17’415 Patients with 37'697 Hospitalisations at a German Psychiatric Hospital. PLoS One, 8, e75612. http://dx.doi.org/10.1371/journal.pone.0075612

[9] Long-Term Care, Health and Welfare Services for the Elderly Ministry of Health, Lavour and Welfare (2015) Elderly Person Care of 2015-For Establishment of the Care to Support the Dignity of the Elderly Person. (In Japanese) http://www.mhlw.go.jp/topics/kaigo/kentou/15kourei/3a.html

[10] Incorporated Administrative Agency National Statistics Center (2013) 2008 Patient Investigation. (In Japanese) http://www.e-stat.go.jp/SG1/estat/NewList.do?tid=000001031167

[11] Nakajima, N., Aiba, M., Fukuda, Y., BokuSoushin, B., Isomura, H., Tuda, H. and Hayashida, Y. (2009) Causes of Death in Hospitalized Elderly Patients. Nihon Ronen Igakkai Zasshi (Japanese Journal of Geriatrics), 46, 71-78. (In Japanese) http://dx.doi.org/10.3143/geriatrics.46.71

[12] NANDA International (2011) Nursing Diagnoses 2012-14 Definitions and Classification. Wiley-Blackwell, Hoboken.

[13] Ogasawara, C., Hasegawa, T., Kume, Y., Takahashi, I., Katayama, Y., Furuhashi, Y., Andoh, M., Yamamoto, Y., Okazaki, S. and Tanabe, M. (2005) Nursing Diagnoses and Interventions of Japanese Patients with End-Stage Breast Cancer Admitted for Different Care Purposes. International Journal of Nursing Terminologies and Classifications, 16, 54-64. http://dx.doi.org/10.1111/j.1744-618X.2005.00014.x

[14] Henderson, V. (1997) Basic Principles of Nursing Care. American Nurses Publishing, Ltd., Washington DC.

[15] Chenitz, W.C. and Swanson, J.M. (1986) From Practice to Grounded Theory: Qualitative Research in Nursing. Addison-Wesley Publishing Company, Menlo Park.

[16] Dorothea, E. and Orem, D.E. (1985) Nursing Concepts of Practice. 3rd Edition, McGraw-Hill, New York.

[17] Minami, H. and Inaoka, F. (1987) A Concept of the Self-Care and Nursing Practice-From a Viewpoint of Dr. P.R. Underwood. Health Publishing Company, Tokyo. 
[18] Okagaki, A., Koretsune, Y., Todo, R. and Kusuoka, H. (2007) Clinical Supporting System in Large-Scaled General Hospital with Customized Interface Layer between Electronic Patient Record System and Filemaker Pro. Proceedings of International Conference on Complex Medical Engineering, Beijing, 23-27 May 2007, 287-290. http://dx.doi.org/10.1109/iccme.2007.4381740

[19] Staggers, N., Weir, C. and Phansalkar, S. (2008) Chapter 47. Patient Safety and Health Information Technology: Role of the Electronic Health Record. In: Hughes, R.G., Ed., Patient Safety and Quality: An Evidence-Based Handbook for Nurses, Agency for Healthcare Research and Quality, Rockville, 251-265.

[20] Population Dynamics, Health Statistics Section Ministry of Health, Lavour and Welfare (2005) The General Condition of 2005 Medical Facilities (Static Condition, Change) Investigation. The Hospital Report. http://www.mhlw.go.jp/toukei/saikin/hw/iryosd/05/kekka1-3.html

[21] Nin, K. (2009) Nursing Process Development Guide-According to Henderson, Gordon, a Framework of NANDA. 2nd Edition, Shorinsha, Tokyo.

[22] Stuart, G.W. and Laraia, M.T. (2005) Principles and Practice of Psychiatric Nursing. 8th Edition, Mosby, Inc., St. Louis.

[23] Matson, J.L., Hattier, M.A., Belva, B. and Matson, M.L. (2013) Pica in Persons with Developmental Disabilities: Approaches to Treatment. Research in Developmental Disabilities, 34, 2564-2571. http://dx.doi.org/10.1016/j.ridd.2013.05.018

[24] Ministry of Health, Labour and Welfare (2007) Health Statistics in Japan 2007. (In Japanese) http://www.mhlw.go.jp/english/database/db-hss/dl/hs2007a.pdf

[25] Central Medical Council, Ministry of Health, Labour and Welfare (2013) About Mind Medical Care. (In Japanese) http://www.mhlw.go.jp/file/05-Shingikai-12404000-Hokenkyoku-Iryouka/0000031076.pdf

[26] Rudnick, A. and Martins, J. (2009) Coping and Schizophrenia: A Re-Analysis. Archives of Psychiatric Nursing, 23, 11-15. http://dx.doi.org/10.1016/j.apnu.2008.02.009

[27] Bowers, L. (2005) Reasons for Admission and Their Implications for the Nature of Acute Inpatient Psychiatric Nursing. Journal of Psychiatric and Mental Health Nursing, 12, 231-236. http://dx.doi.org/10.1111/j.1365-2850.2004.00825.x

[28] Kataoka, M., Ozawa, K., Tanioka, T. and Locsin, R. (2015) Clarifying the Strengths-Oriented Attitude among Nurses in Psychiatric Hospitals in Japan. Health, 7, 776-787. http://dx.doi.org/10.4236/health.2015.76092

[29] Boykin, A. and Schoenhofer, S.O. (2001) Caring: A Model for Transforming Practice. Jones \& Bartlett Learning, Burlington.

[30] Evansa, J.D., Heatona, R.K., Paulsenc, J.S., Palmera, B.W., Pattersona, T. and Jestea, D.V. (2003) The Relationship of Neuropsychological Abilities to Specific Domains of Functional Capacity in Older Schizophrenia Patients. Biological Psychiatry, 53, 422-430. http://dx.doi.org/10.1016/S0006-3223(02)01476-2

[31] Sawada, A., Porter, S.E., Kayama, M., Setoya, N. and Miyamoto, Y. (2006) Nursing Care Delivery in Japanese Psychiatric Units. British Journal in Nursing, 15, 920-925. http://dx.doi.org/10.12968/bjon.2006.15.17.21906

[32] Sano, T., Harada, M., Sugawara, T., Isaka, N., Masuoka, A., Mikami, A., Shimamori, Y. and Kurosawa, N. (2013) Use of Psychotropics and the Risk of Falls in Hospitalized Psychiatric Patients. Yakugaku Zasshi, 133, 897-903. (In Japanese) http://dx.doi.org/10.1248/yakushi.13-00003

[33] Stenhagen, M., Ekström, H., Nordell, E. and Elmståhl, S. (2014) Both Deterioration and Improvement in Activities of Daily Living Are Related to Falls: A 6-Year Follow-Up of the General Elderly Population Study Good Aging in Skåne. Clinical Interventions in Aging, 9, 1839-1846. http://dx.doi.org/10.2147/CIA.S70075

[34] Soderqvist, A., Stromberg, L., Ponzer, S. and Tidermark, J. (2006) Documenting the Cognitive Status of Hip Fracture Patients Using the Short Portable Mental Status Questionnaire. Journal of Clinical Nursing, 15, 308-314. http://dx.doi.org/10.1111/j.1365-2702.2006.01296.x

[35] Gallego, A.J., Nielsen, J., Hert, D.M., Kane, J.M. and Correll, C.U. (2012) Safety and Tolerability of Antipsychotic Polypharmacy. Expert Opinion on Drug Safety, 11, 527-542. http://dx.doi.org/10.1517/14740338.2012.683523

[36] Steven, J.W. and Gerrit, W.C. (1996) Development of a Policy on Sexuality for Hospitalized Chronic Psychiatric Patients. Canadian Journal of Psychiatry, 41, 273-279.

[37] Tanioka, T., Mano, M., Takasaka, Y., Tada, T. and Kawanishi, C. (2006) Challenge of Psychiatric Rehabilitation for Patients with Long-Term Hospitalizations Using the Nirje's Normalization Principles as a Valuation Standard: Two Case Studies. The Journal of Medical Investigation, 53, 209-217. http://dx.doi.org/10.2152/jmi.53.209 